\title{
EDitorial
}

\section{Knowledge and the curriculum}

\section{Carol Mutch}

Recently, I had the opportunity to listen to Michael F. D. Young, whose book Knowledge and Power (1971) was very influential on my early thinking about curriculum. Michael Young is an emeritus professor at the University of London and was in New Zealand to give the prestigious Hood lecture at The University of Auckland. He began his talk, titled "Curriculum for a knowledge society: Lessons from the sociology of knowledge", with this challenge:

Much is written in current educational policies about preparing students for a knowledge society and the important role education has to play. However, these policies say very little about the question of knowledge itself. What is it we want young people to know? More worrying than this, many of these policies almost systematically neglect or marginalise the question of knowledge ... ${ }^{1}$

Professor Young went on to distinguish between a traditional view of a subject-based curriculum and his view of a reconceptualised curriculum. The former, he claimed, is something that students comply with, and the latter is something that students acquire by engagement. His argument against the current curriculum reforms in the United Kingdom is based on his concern about the notion of viewing curriculum as an instrument for "motivating students". He contends that this (a) misunderstands what curriculum can do and (b) confuses curriculum with pedagogy. Curriculum he defines as the knowledge that a country agrees is important for all students to have access to, and pedagogy as the activities that teachers use to motivate students and enable them to engage with concepts stipulated by the curriculum.

While I didn't always agree with aspects of Professor Young's argument as it developed in his lecture, he did put up challenges that were worthy of consideration. It made me reflect on the body of knowledge that we in New Zealand consider is essential for our learners to engage with. What 
and whose knowledge is important? Who chooses this knowledge and with what authority?

Professor Young went on to argue that the curriculum needs to be seen as an end in itself, that is, for the intellectual development of students, not as a means, for example, of motivating disaffected students or solving social problems. This intellectual development is concept-based rather than content-based, but there must be content on which to build this conceptual understanding. The conceptual knowledge base, he claims, comes from specialist fields developed by scholars and communities of researchers over time. The claim he made that I found most challenging was this: "The curriculum should exclude the everyday knowledge of students, whereas it is a resource for the pedagogic work of teachers." He continued, "Students do not come to school to learn what they already know."

Professor Young was very clear in his mind where the boundary lay between curriculum and pedagogy, between an agreed intellectual knowledge base and the links that teachers make to students' own knowledge and experiences. To paraphrase his words, curriculum is the agreed intellectual knowledge base and pedagogy is the work teachers undertake to draw on students' everyday knowledge to enable them to engage with and understand the relevance of the concepts in this knowledge base.

Following on from this premise, the world and the concepts within it need to be viewed as an "object of thought" not as a "place of experience". Let me quote his example:

If pupils cannot grasp the difference between thinking about Auckland as an example of the geographical concept of a city and their experience of living in Auckland, when they draw on their everyday concepts they will have problems learning geography, and by analogy, any school subject that seeks to take them beyond their experience [his emphasis].

He continued to explain that teachers, therefore, had two fundamental tasks:

1. helping students manage the relationship between the concepts of the different subjects that make up their referents in everyday life 
2. introducing students to concepts whose meaning does not derive from their experience.

While Professor Young had more to say, this seems a useful place to turn to a discussion of the articles in this year's edition of Curriculum Matters. In what ways do these articles confirm or refute Professor Young's thesis?

James Magrini's article is an interesting place to continue considering the knowledge base of the curriculum. Magrini argues that we cannot debate the place of knowledge in the curriculum until we better understand how knowledge is constructed. Using concepts drawn from philosophy, Magrini explains, with examples from the reading debates, how competing educational theories and their contrasting pedagogical practices come from differing epistemological beliefs. He then outlines the usefulness of touchstone theory for enabling educators to make sense of competing approaches, such as the essentialist and instrumentalist ones he uses in his article.

David Bell considers the place of knowledge in the curriculum through the lens of teachers' subject knowledge. He puts this in the context of the visual arts in the curriculum, which he sees is being eroded by competing interests and fiscal restraints. Bell would see the relationship between curriculum and pedagogy as more integrated than does Michael Young. He describes learning as "a contextualised experience, defined through the developing interactions between child, teacher, subject knowledge and community cultures". He concludes that the visual arts contribute more than content to a well-balanced curriculum - they add aspects that are multidimensional, nuanced, interactive, reflective, intuitive, imaginative and inventive.

Cheryl Craig's article focuses on curriculum at a theoretical level, particularly the theory-practice divide. She contends that there is a disconnect between curriculum theorists and practitioners. In order to explain her concerns, she turns to Schwab, who first raised this issue in 1969. Using Schwab's six characteristic "flights from the field" in the context of teacher education, Craig provides both a personal narrative and a speculation on the future field of curriculum. She suggests seven possible areas of focus for future curriculum research-the final one being: which curriculum questions are worth asking? 
Maree Jeurissen's article returns to the question of what knowledge is important - in her case, for teachers, in order to teach and assess literacy accurately. Jeurissen contends that despite professional development programmes provided throughout the 1990s as part of the Exploring Language project, teachers in New Zealand lack sufficient declarative knowledge of grammar to teach and assess literacy in the current curriculum. She claims that this is a concern given the implementation of National Standards and the expectation that teachers will make overall judgements about students' proficiency against these standards. Jeurissen canvasses the overseas literature and finds that the lack of grammatical knowledge is not just a New Zealand problem. She concludes that this needs to be addressed with some urgency.

Martyn Davison's article has resonances with David Bell's article on visual arts, in that they both go beyond the knowledge base of the curriculum into affective aspects. Davison focuses on empathy in the history classroom. He makes links with the current curriculum document through the development of key competencies, such as relating to others, and through the content of the historical themes in the social sciences achievement objectives. He uses a range of local and overseas studies to explore the successes and limitations of getting students to feel empathy with the lives and events of the people in their historical studies.

Vicki Carpenter and Debora Lee use the lens of the hidden curriculum to explore whose knowledge is important within teacher education. The authors use a very broad definition of curriculum, which includes formally documented content, the theoretical underpinnings of this content and the way in which it is delivered. They also explain that those who deliver it give overt or covet messages about what matters through their visible genders, social class backgrounds, ethnicities and sexualities, and through their values, discursive practices and dispositions. The voices of both LGBTT (lesbian, gay, bisexual, transgender and transsexual) and heterosexual participants in their study give an insight into the invisibility of LGBTT people in the context of the teacher education curriculum and beyond.

Whose knowledge is important is also a question at the heart of the final article by Ruth Reynolds and Sue Lane. Using Bourdieu's notions 
of field, capital and habitus, they explore the ways in which different participants in the same project brought quite different conceptions of whose knowledge is important and how it should be imparted. Their action research approach allowed for plenty of reflection on the assumptions, expectations and frustrations of the participants, as a group of teacher educators in Australia attempted to work with local African communities to build more tolerance and understanding in local schools.

Reynolds and Lane conclude, "Going out of your comfort zone to address an issue is a journey that involves a constant state of self-reflection and emotional turmoil. We need teaching to continue to be a contestation of differing views and a site of turmoil if we are to engage with others meaningfully." I would add that we need to keep this contestation alive in curriculum studies and continue to ask: What and whose knowledge is important? What is curriculum and what is pedagogy? Is knowledge more important than other aspects of the curriculum? Which curriculum questions are worth asking? Whose voices are heard and whose are silenced? Curriculum Matters offers a vehicle to consider these and other vital issues.

\section{Reference}

Young, M. D. F. (Ed.). (1971). Knowledge and power. London: Collier-Macmillan.

\section{Notes}

1. I am grateful to the School of Critical Studies in Education in the Faculty of Education at The University of Auckland for providing me with Professor Young's speech notes.

\section{The author}

Carol Mutch is currently the Senior Advisor to the Chief Review Officer in the Education Review Office. Formerly a teacher, teacher educator and academic, Carol's research and writing interests are in educational policy, curriculum, educational research and evaluation, and social education. She is the author of Doing Educational Research: A Practitioner's Guide to Getting Started and editor of Challenging the Notion of "Other" : Reframing Research in the Aotearoa New Zealand Context. 